\title{
EDITORIAL, V. 25, N. 1, JAN./ABR. 2021 \\ COMUNICAÇÃO E DIVULGAÇÃO CIENTÍFICA, UM ATO DE POLÍTICA PÚBLICA
}

\author{
EDITORIAL, V. 25, N. 1, ENERO/ABR. 2021 \\ COMUNICACIÓN Y DIVULGACIÓN CIENTÍFICA, UN OBJETIVO DE POLÍTICA \\ PÚBLICA
}

EDITORIAL, V. 25, N. 1, JAN./APR. 2021

SCIENCE COMMUNICATION AND DISSEMINATION, AN ACT OF PUBLIC POLICY

Sebastião de Souza LEMES ${ }^{1}$

José Anderson SANTOS CRUZ ${ }^{2}$

Flávio Henrique MACHADO MOREIRA ${ }^{3}$

Julio Cesar TOMASI CRUZ ${ }^{4}$

Alexander Vinícius LEITE DA SILVA ${ }^{5}$

A Revista on line de Politica e Gestão Educacional - RPGE publicou seu primeiro número no ano de 2001 e completa 21 anos de existência neste ano de 2021. Na sua trajetória, a RPGE passou por várias mudanças - da publicação semestral a quadrimestral, novos indexadores, internacionalização, implementação da plataforma Open Journal System (OJS) -, além das melhorias quanto ao design e processos de gestão editorial.

Atualmente, e de forma constante, a RPGE tem como valores essenciais a qualidade dos artigos e de suas publicações, o parecer ético com diálogo contínuo e humanizado com os autores e a formação técnica e científica da equipe editorial, a qual vem se destacando pela gestão editorial para os processos que uma revista científica aplica desde o recebimento da submissão até a publicação do artigo.

${ }^{1}$ Universidade Estadual Paulista (UNESP), Faculdade de Ciências e Letras, Araraquara - SP - Brasil. Professor do Departamento de Educação e Coordenador do Programa de Pós-Graduação em Educação Escolar. Editor. ORCID: https://orcid.org/0000-0002-0750-9294. E-mail: ss.lemes@gmail.com

${ }^{2}$ Universidade Estadual Paulista (UNESP), Faculdade de Ciências e Letras, Araraquara - SP - Brasil. Doutor pelo Programa de Pós-graduação em Educação Escolar. Editor Adjunto e Executivo da RPGE. Assessoria Técnica para periódicos da Educação. Prof. Orientador PECEGE - MBA/USP ESALQ. Editor responsável pela Editora IberoAmericana de Educação. ORCID: http://orcid.org/0000-0001-5223-8078. $\quad$ E-mail: andersoncruz.unesp@gmail.com

${ }^{3}$ Universidade Federal de São Carlos (UFSCAR), São Carlos - Brasil. Assistente Editorial da RPGE. Mestre em Ciência Política. ORCID: https://orcid.org/0000-0002-2659-1692. E-mail: flavio.machadomoreira@gmail.com

${ }^{4}$ Faculdade de Tecnologia de Praia Grande (FATEC PG), Praia Grande - SP - Brasil. Graduado em Tecnologia em Gestão Empresarial. Assistente Editorial da RPGE. Editor Assistente na Editora Ibero-Americana de Educação. ORCID: https://orcid.org/0000-0001-8775-8727. E-mail: juliotomasi@editoraiberoamericana.com

${ }^{5}$ Centro Universitário Sagrado Coração (UNISAGRADO), Bauru - SP - Brasil. Graduando em Letras. Bolsista PIBID/CAPES. Assistente Editorial da RPGE. Revisor e tradutor português/inglês. ORCID: https://orcid.org/0000-0002-4672-8799. E-mail: alexandervinicius@editoraiberoamericana.com 
O processo editorial, requer tanto do Editor quanto da Equipe Editorial conhecimentos prévios das atribuições e das configurações da revista. Para isso, conhecer as etapas, os procedimentos e as funções de cada integrante da equipe são fundamentais para que a revista seja bem gerida, e que se possa validar suas publicações em volumes e edições. Esse conhecimento prévio torna o fluxo editorial mais ágil para as realizações de cada etapa, principalmente no que envolve planejar, organizar, atribuir e aplicar as experiências adquiridas por meio das informações técnicas e conceituais acerca do periódico (SANTOS CRUZ, 2020, p. 74).

O quadriênio 2017-2020 foi particularmente importante para nós, pois foram anos de várias conquistas como: indexar a revista na Web of Science: Emerging Sources Citation Index, Redalyc, MIAR, Erihplus, Index Copernicus, Redib, Edubase, DOAJ etc. entre outras bases, diretórios e divulgadores de significativa importância no circuito de periódicos da área de Educação. Nesse período,

Dois movimentos podem ser identificados no processo: 1) a exigência por qualidade detectável nas avaliações estabelecida pelos critérios das Coordenações de Área da CAPES, nas quais cada periódico recebe uma nota; e 2) a exigência de qualidade detectável nos processos de gestão dos periódicos, os quais determinam a resposta das Equipes Editoriais frente às questões como recepção e avaliação de manuscritos, eficiência nos processos de produção editorial, busca por indexação em bases, repositórios e divulgadores nacionais e internacionais (SANTOS CRUZ, 2020, p. 35).

Outro fator essencial para o processo de internacionalização e reconhecimento foi o início das publicações no formato bilíngue (português e inglês), o qual foi e continua sendo relevante para a revista, principalmente para as publicações de nossos autores, já que a visibilidade e o alcance estão em crescimento constante, como demonstra a Figura 1:

Figura 1 - Visibilidade internacional da RPGE

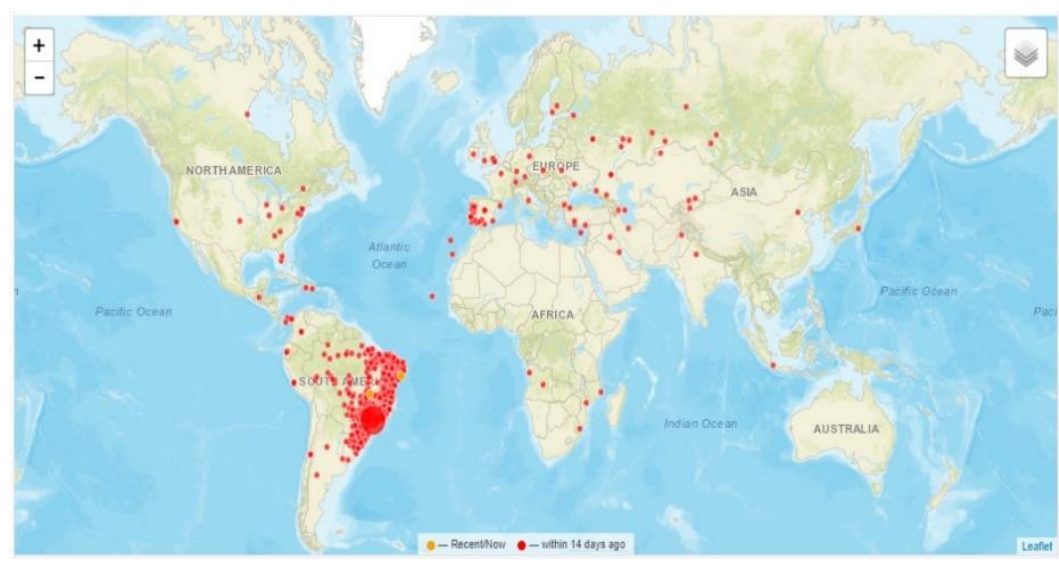


Fonte: Clustmaps (2021) - visibilidade em 01/01/2021

Como mostra o mapa (Figura 1) é possível verificar a distribuição pelos diferentes países que a RPGE é acessada. Isso revela, entre os trabalhos e esforços, a eficácia do processo de gestão de editoria aliada às estratégias de comunicação em âmbito nacional e internacional desenvolvida por todos que atuam nos bastidores da revista. Nesse sentido, no Quadro 1, podemos averiguar o crescimento de acessos e downloads dos nossos artigos de forma crescente.

Quadro 1 - RPGE - acessos e downloads

\begin{tabular}{|c|c|c|}
\hline ANO & Visualização & Downloads do PDF \\
\hline 2016 & - & - \\
\hline 2017 & 42.370 & 34.767 \\
\hline 2018 & 92.255 & 99.440 \\
\hline 2019 & 139.395 & 142.977 \\
\hline 2020 & 224.818 & 164.734 \\
\hline TOTAL & 498.838 & 441.918 \\
\hline
\end{tabular}

*Em 2016 a RPGE não estava na plataforma OJS.

Fonte: Open Journal System (OJS) - Elaboração pelos autores

Como Santos Cruz (2018) aponta, outro fator relevante nesse processo é que para os periódicos se qualificarem e adentrarem no rol de alguns indexadores, eles necessitam publicar no formato bilíngue e em XML (linguagem de marcação), além de manter um quadro de profissionais atuantes no processo de revisão, formatação, normalização, comunicação, divulgação e desenvolvimento de estratégias de ação e divulgação dos estudos e pesquisas educacionais. Tudo isso para permanecerem entre outros periódicos de credibilidade e confiabilidade, apesar da demanda de custos que isso produz.

Com essa visibilidade, a RPGE, nesse momento, investe no processo editorial, na comunicação direta com os autores e na estruturação da revista. $\mathrm{O}$ aprendizado que se obteve na trajetória até a maioridade mostrou - e ainda mostra - a necessidade de se empreender na manutenção dos esforços até aqui empregados e de se buscar outros que nos aprimore no atendimento das demandas as quais nos submetemos pelas exigências da divulgação científica tão necessária na atualidade. Os periódicos são de fundamental importância como meios

${ }^{6}$ Disponível em: https://clustrmaps.com/site/1813n. Acesso em: 20 mar. 2021. 
científicos e na comunicação entre a comunidade científica e a sociedade em geral. $\mathrm{O}$ volume de informações cientificamente produzida e distribuída, ou seja, o conhecimento compartilhado é um imperativo ético de responsabilidade democrática e social. O alcance, a visibilidade e a credibilidade conquistados pela RPGE é o tributo que pagamos à democracia e a sociedade. A divulgação científica se constitui em instrumento de visibilidade e de legitimidade das ciências.

Com isso, a RPGE, em sua busca constante do atendimento aos compromissos assumidos, a Figura 2 abaixo mostra o crescimento em citações verificado no Índice $h$ apontado do Google Scholar.

Figura 2 - Citações e Índice h RPGE

\begin{tabular}{|c|c|c|}
\hline \multirow[t]{2}{*}{ Citado por } & \multicolumn{2}{|c|}{ VISUALIZAR TODOS } \\
\hline & Todos & Desde 2016 \\
\hline Citações & 779 & 696 \\
\hline Índice h & 11 & 11 \\
\hline Índice i10 & 18 & 14 \\
\hline & & 320 \\
\hline & & 240 \\
\hline & & 160 \\
\hline & & 80 \\
\hline $2014 \quad \square 015 \quad 20$ & & 2021 \\
\hline
\end{tabular}

Fonte: Google Scholar (2021) - RPGE

Nesse contexto, observa-se que as citações estão em uma crescente. Em 2017 e 2018, momento em que a RPGE se fidelizou ao Open Journal System - plataforma de submissões e de fluxo editorial -, os artigos ficaram mais vísivies à comunidade científica da área de Educação, aos professores, outros pesquisadores e para a sociedade em geral. No período compreendido entre os anos de 2019 e 2020, a revista conseguiu sua indexação em mais duas bases de dados internacionais importantes, a Web of Science e a Redalyc, nessas há exigência de obrigatoriedade dos textos estarem em formato bilingue para sua publicação.

O processo da gestão editorial visa garantir a credibildiade do periódico, essa credibildiade se conquista com respeito aos autores, qualidade no processamento dos artigos e nas indexações, pois se faz necessário entender que no processo de indexação cada base possui critérios rigorosos de aceitação. A revista, os autores e a equipe editorial também se tansformam com essas mudanças para garantir a inclusão, mas prncipalmente a permanência. 
Nesse momento a RPGE assume o seu papel para além de seus meios consciente de que o conhecimento compartilhado é instrumento de inclusão, é defesa do estado democrático de direito, é esclarecimento e ação política.

Agradecemos a todos que fazem parte dessa equipe editorial, aos autores, aos leitores.

\section{REFERÊNCIAS}

SANTOS CRUZ, J. A. Editorial (v.14, n.1, jan./jun. 2018) - Education and management of newspapers: new paths and perspectives in science. Temas em Educação e Saúde (Themes in Education and Health), Araraquara, v. 14, n. 1, p. 1-4, 2018. DOI:

https://doi.org/10.26673/rtes.v14.n1.2018.11516

SANTOS CRUZ, J. A. Editorial, v. 14, n. 2, jul./dez. 2018. Acesso aberto e a publicação científica. Temas em Educação e Saúde (Themes in Education and Health), Araraquara, v. 14, n. 2, p. 211-214, 2018. DOI: https://doi.org/10.26673/tes.v14i2.12030

SANTOS CRUZ, J. A. Gestão do conhecimento e gestão editorial: qualificadores da avaliação de periódicos da Área de Educação. Orientador: Prof. Dr. José Luís Bizelli. 2020. 283 f. Tese (Doutorado em Educação Escolar) - Faculdade de Ciências e Letras, Universidade Estadual Paulista, Araraquara, SP, 2021.

\section{Como citar este documento}

LEMES, S. S.; SANTOS CRUZ, J. A.; MACHADO MOREIRA, F. H.; TOMASI CRUZ, J. C.; LEITE DA SILVA, A. V. Editorial, v. 25, n. 1, jan./abr. 2021: Comunicação e Divulgação Científica, um ato de Política Pública. Revista online de Política e Gestão Educacional, Araraquara, v. 25, n. 1, p. 1-5, jan./abr. 2021. e-ISSS: 1519-9029. DOI: https://doi.org/10.22633/rpge.v25i1.15034

Submetido em: 02/01/2021

Pulicado em: 02/01/2021 